\title{
A Novel Process for the Production of Aromatic Hydrocarbons from Brown Coal in Water Medium by Hydrothermal Oxidation and Catalytic Hydrothermal Decarboxylation
}

\author{
Qingxin Zheng, ${ }^{1}$ Masato Morimoto, ${ }^{1 *}$ and Toshimasa Takanohashi ${ }^{1 *}$
}

1 Non-conventional Carbon Resources Group, Research Institute of Energy Frontier, National Institute of Advanced Industrial Science and Technology (AIST), 16-1 Onogawa, Tsukuba 305-8569, Japan

* Corresponding authors.

E-mail addresses: m.morimoto@aist.go.jp (M. Morimoto) and toshi-takanohashi@aist.go.jp (T. Takanohashi). 


\begin{abstract}
With no use of hydrogen or a hydrogen donor, a novel process is proposed for the production of aromatic hydrocarbons from brown coal in water medium, which consists of hydrothermal oxidation at $240^{\circ} \mathrm{C}$ and $\mathrm{Cu}_{2} \mathrm{O}$-catalysed hydrothermal decarboxylation at $350^{\circ} \mathrm{C}$. Using this hydrothermal oxidation and catalytic hydrothermal decarboxylation method, aromatic carboxylic acids were formed from brown coal by an oxidation process, and then decarboxylated to the corresponding aromatic hydrocarbons. The validity of the decarboxylation method was examined using several aromatic carboxylic acids as model compounds for the acid products after hydrothermal oxidation of brown coal, including o-phthalic acid, isophthalic acid, terephthalic acid, hemimellitic acid, trimellitic acid, trimesic acid, 1-naphthoic acid, 2-naphthoic acid, and 2,6-naphthalic acid. Use of $\mathrm{s} \mathrm{Cu}_{2} \mathrm{O}$ catalyst increased the decarboxylation yields of all the aromatic carboxylic acids. Especially for benzene carboxylic acids, all decarboxylation yields were above $90 \%$ with $100 \%$ selectivity. The $\mathrm{Cu}_{2} \mathrm{O}$-catalysed hydrothermal method was proven to be effective, not only for the decarboxylation reactions from monocarboxylic acids to hydrocarbons, but also for the decarboxylation reactions from tricarboxylic acids to dicarboxylic acids and from dicarboxylic acids to monocarboxylic acids. In the presence of alkali and oxygen during the oxidation process, various valuable aromatic hydrocarbons and heterocyclic compounds, especially benzene, were obtained from Loy Yang coal using the hydrothermal oxidation and catalytic decarboxylation process. Based on analyses of aromatic carboxylic acids or ions before and after the decarboxylation process, it was found that decarboxylation reactions were the major reactions and the use of $\mathrm{Cu}_{2} \mathrm{O}$ was effective not only for the decarboxylation from monocarboxylic acids but also from polycarboxylic acids to monocarboxylic acids, consistent with the results for the model aromatic carboxylic acids. Additionally, it was found that a $\mathrm{Cu}_{2} \mathrm{O}$ catalyst was also effective for the conversion of 'heavy' compounds in oxidised coal to 'light' compounds.
\end{abstract}

Keywords: brown coal; aromatic hydrocarbons; hydrothermal oxidation; hydrothermal decarboxylation; $\mathrm{Cu}_{2} \mathrm{O}$. 


\section{Introduction}

Brown coal, or lignite, is abundant worldwide at a much cheaper price than high-rank coal, and is regarded as one of the most important resources for chemicals, especially aromatic hydrocarbons, due to its rich aromatic content.[1] Despite its high moisture content, low heating value - caused by intrinsic oxygen functional groups[2] - and high spontaneous combustibility after drying, there are many methods to produce aromatic hydrocarbons from brown coal, such as pyrolysis, direct liquefaction, and indirect liquefaction. However, the need for high energy during the drying process, high temperature, and the use of expensive hydrogen or hydrogen donors are obvious drawbacks.

A combination method of oxidation and decarboxylation is a feasible approach to convert brown coal to aromatic hydrocarbons with no use of hydrogen or hydrogen donors under mild conditions.[3-8] In the oxidation process, aromatic carboxylic acids are obtained from coal, and then during the decarboxylation process, carboxylic functional groups in aromatic carboxylic acids are removed to form aromatic hydrocarbons. Because the moisture content of brown coal is usually higher than $50 \%$ and the drying process consumes a large amount of energy, it is significant to realise both oxidation and decarboxylation processes in a water medium. Scheme 1 shows the concept of hydrothermal oxidation and hydrothermal decarboxylation process for the production of aromatic hydrocarbons from brown coal. The solid and dash lines correspond to the conventional processes and our proposed processes, respectively.

Most oxidation methods for the production of aromatic carboxylic acids from coal are performed in aqueous media,[9] such as the alkali- $\mathrm{O}_{2}$ method,[10-12] the $\mathrm{H}_{2} \mathrm{O}_{2}$ method,[13] and the $\mathrm{HNO}_{3}$ method.[14] However, the high stability of aromatic carboxylic acids in hot water limits their further hydrothermal decarboxylation to aromatic hydrocarbons greatly.[15] Cu-based, Ag-based, and Pd-based catalysts have been shown to be effective for the decarboxylation or protodecarboxylation of aromatic carboxylic acids, but usually organic solvents, such as quinoline, N-methylpyrrolidone, tetrahydrofuran, dimethyl sulphoxide, or toluene,[16-25] are indispensable. At present, it is still rare to use a catalyst for the hydrothermal decarboxylation of aromatic carboxylic acids. In 2004, Matsubara and coworkers reported the combination of a palladium catalyst and hydrothermal water.[26] At $250^{\circ} \mathrm{C}$ and $5 \mathrm{MPa}$ for $14 \mathrm{~h}, 1$-naphthoic acid was converted to naphthalene in $74 \%$ yield. Then, in 2015, our group realised the efficient decarboxylation of stable benzoic acid to benzene using a $\mathrm{Cu}_{2} \mathrm{O}$ catalyst and subcritical water at $350^{\circ} \mathrm{C}\left(\mathrm{Cu}_{2} \mathrm{O}-\mathrm{SbCW}\right.$ system).[27] The conversion yields reached more than $90 \%$ in 90 min with $100 \%$ selectivity. This result was only about the reaction from benzoic acid to benzene, but it was enlightening to break though the bottleneck of the hydrothermal decarboxylation of aromatic carboxylic acids, and helpful to finally achieve the production of aromatic hydrocarbons from brown coal by hydrothermal oxidation and hydrothermal decarboxylation. Considering the various reported mono- and polycarboxylic acids obtained from the oxidation of brown coal, such as the benzene carboxylic acids, [28] it is important to study the applicability of the $\mathrm{Cu}_{2} \mathrm{O}-\mathrm{SbCW}$ system to different carboxylic acids before examining oxidised brown coal.

Here, the decarboxylations of model aromatic carboxylic acids including $o$-phthalic acid, isophthalic acid, terephthalic acid, hemimellitic acid, trimellitic acid, trimesic acid, 1naphthoic acid, 2-naphthoic acid, and 2,6-naphthalic acid, were performed using the $\mathrm{Cu}_{2} \mathrm{O}$ $\mathrm{SbCW}$ system. Furthermore, the $\mathrm{Cu}_{2} \mathrm{O}-\mathrm{SbCW}$ system was used to perform the decarboxylation of the products prepared by the hydrothermal oxidation of brown coal, with no use of hydrogen or hydrogen donors. 


\section{Experimental}

2.1. Coal sample. Australian brown coal, Loy Yang coal (LY), was used without drying or grinding. Table 1 shows the ultimate and proximate analyses of LY, including elemental compositions, fixed carbon (FC) and volatile matter (VM) contents, ash content, and water content (moisture). LY had a high moisture content, of $58.4 \%$, and a high oxygen content, of $27 \%$. The ash content of LY was only $1.5 \%$, and the sulphur content was as low $(0.2 \%)$.

2.2. Chemical reagents. The aromatic carboxylic acids included benzoic acid, $o$-phthalic acid, isophthalic acid, terephthalic acid, hemimellitic acid, trimellitic acid, trimesic acid, 1naphthoic acid, 2-naphthoic acid, and 2,6-naphthalic acid. The information of all the model aromatic acids was shown in Table $\mathrm{S} 1$. Copper (I) oxide $\left(\mathrm{Cu}_{2} \mathrm{O}, 99.5 \%\right.$, powder, Wako Pure Chemical Industries, Ltd.) was used as a catalyst, with no further modification. The surface area of commercial $\mathrm{Cu}_{2} \mathrm{O}$ was $0.7 \mathrm{~m}^{2} / \mathrm{g}$. The organic solvent dichloromethane $\left(\mathrm{CH}_{2} \mathrm{Cl}_{2}, 99.5 \%\right.$, Wako Pure Chemical Industries, Ltd.) was used for product recovery and analyses.

2.3. Apparatus. The apparatus consisted of a cylinder-shaped autoclave with an internal volume of $50 \mathrm{~cm}^{3}$ and a rocking electric furnace.[27] The autoclave was equipped with a pressure gauge amplifier and a thermocouple to monitor the inner pressure and temperature, respectively.

2.4. Hydrothermal decarboxylation of model aromatic carboxylic acids. The experimental process followed our previous report.[27] The model carboxylic acids used here include six benzene carboxylic acids (o-phthalic acid, isophthalic acid, terephthalic acid, hemimellitic acid, trimellitic acid, and trimesic acid) and three naphthalene carboxylic acids (1-naphthoic acid, 2 naphthoic acid and 2,6-naphthalic acid). All relevant decarboxylation reactions were shown in Chart 1 and can be expressed by reactions (I) to (XIII).

In a typical experiment about the hydrothermal decarboxylation of $o$-phthalic acid, $1.2162 \mathrm{~g}$ of $\mathrm{Cu}_{2} \mathrm{O}, 1.4337 \mathrm{~g}$ of $o$-phthalic acid, and $28.1 \mathrm{~g}$ of distilled water were fed into the autoclave and the interior air was replaced with nitrogen. The autoclave was inserted into the furnace, heated to the desired temperature. The temperature and pressure inside the autoclave were recorded during each reaction. The time required to reach $350^{\circ} \mathrm{C}$ was $\sim 26 \mathrm{~min}$ and the pressure increased from an initial pressure of $0.1 \mathrm{MPa}$ to autogenous pressures. After the desired 60min reaction time, the autoclave was removed from the furnace and allowed to cool to room temperature. The gaseous product ( $\sim 99.9 \%$ of that is carbon dioxide) was collected in a gas bag by washing with nitrogen. The other products, which were the oil and water phases, and the solid catalyst, were recovered by inverting the autoclave and washing with $\mathrm{CH}_{2} \mathrm{Cl}_{2}$. After centrifugation $(6,000 \mathrm{rpm}, 15 \mathrm{~min})$, the solid catalyst was separated from the solution and dried at $80^{\circ} \mathrm{C}$ for $24 \mathrm{~h}$ in a vacuum oven. The remaining solutions, composed of the oil phase fraction dissolved in $\mathrm{CH}_{2} \mathrm{Cl}_{2}$ and the $\mathrm{H}_{2} \mathrm{O}$ phase fraction, were separated using a separating funnel. Benzene or naphthalene was mostly obtained from the oil phase fraction. More information regarding the experimental procedures is provided in Table 2 and Table S2. All experiments were repeated twice.

During the decarboxylation reactions of the model aromatic carboxylic acids, there is some relationship between the decarboxylation yield of an acid and the conversion yield of its decarboxylation reaction. For example, for the decarboxylation reaction from benzoic acid to benzene, the decarboxylation yield of benzoic acid is equal to the conversion yield of the decarboxylation reaction, from benzoic acid to benzene. However, for the decarboxylation reaction of $o$-phthalic acid, there are two decarboxylation reactions, that from $o$-phthalic acid to benzoic acid (reaction (II)) and that from benzoic acid to benzene (reaction (I)). If the decarboxylation yield of $o$-phthalic acid is set as DY-a, the conversion yield of 
decarboxylation reaction from $O$-phthalic acid to benzoic acid is set as CY-II, and the conversion yield of the decarboxylation reaction from benzoic acid to benzene is set as CY-I, then the relationship between them can be described in equation (1).

$\mathrm{CY}-\mathrm{II} \times(1+\mathrm{CY}-\mathrm{I})=2 \times \mathrm{DY}-\mathrm{a}$

As the conversion yield of reaction (I) was $2.4 \%$ and $87.4 \%$, without and with a $\mathrm{Cu}_{2} \mathrm{O}$ catalyst, respectively,[27] and DY-a was obtained directly using the amount of carbon dioxide, it is easy to calculate CY-II. By following this method and under the assumption that the decarboxylation yields of all the model carboxylic acids are fixed, the exact conversion yields of decarboxylation reactions (II), (III), (IV), (X), (XI), (XII), and (XIII) can be calculated readily. However, for the decarboxylation reaction of hemimellitic acid and trimellitic acid, there is more than one decarboxylated benzene dicarboxylic acid and the ratio of them is unknown, so only the relationship between the conversion yields of different reactions can be obtained.

2.5. Hydrothermal oxidation and hydrothermal decarboxylation of $L Y$. The process is shown in Scheme 2. In a typical experiment, $2.5 \mathrm{~g} \mathrm{LY}, 1 \mathrm{~g} \mathrm{NaOH}$, and $20 \mathrm{~g}$ distilled water, were fed into the autoclave. The interior air was replaced with oxygen, and the pressure was maintained at 5.0 MPa. The autoclave was inserted into the furnace, heated to $240^{\circ} \mathrm{C}$. After a 30-min reaction time, the autoclave was removed from the furnace and cooled to room temperature rapidly. The gaseous products were collected in a gas bag, as Gas 1. After filtration, the residue and aqueous solution were separated, as Residue 1 and Liquid 1, respectively. Then, Liquid 1 was acidified to neutral with $\mathrm{H}_{2} \mathrm{SO}_{4}$ and a large amount of gas was emitted, as Gas 2. After another filtration, the residue was obtained as Residue 2, and the yellow transparent solution (Liquid 2) was poured back into the autoclave. Then, $1 \mathrm{~g} \mathrm{Cu}_{2} \mathrm{O}$ and $8 \mathrm{~g}$ distilled water were added, and the interior air was replaced with nitrogen. The autoclave was heated up to $350^{\circ} \mathrm{C}$ at a rate of $\sim 12.5^{\circ} \mathrm{C} / \mathrm{min}$. After a $60-\mathrm{min}$ reaction time, the autoclave was removed from the furnace and allowed to cool to room temperature. The gaseous product was collected in a gas bag by washing with nitrogen, as Gas 3. The other products, which were oil and water phases, were recovered by inverting the autoclave and washing with $\mathrm{CH}_{2} \mathrm{Cl}_{2}$. After centrifugation, the solid catalyst was separated from the solution and the remaining solutions, composed of the oil phase fraction dissolved in $\mathrm{CH}_{2} \mathrm{Cl}_{2}$, and a water phase fraction, were separated using a separation funnel. The experiment without $\mathrm{Cu}_{2} \mathrm{O}$ was used as the reference.

2.6. Analyses. The volume and composition of the gaseous products were measured using a cylinder and a gas chromatograph (GC, GC-3200, GL Science Inc., Tokyo, Japan), respectively. Compounds in the oil and water phase were identified using gas chromatography-mass spectrometry (GC-MS, HP 6890 series GC system with 5973 mass selective detector, Hewlett Packard, Palo Alto, CA, USA) with Agilent 19091A-105 column and gas chromatograph-flame ionization detector (GC-FID, HP 6890 series GC system, Hewlett Packard) with Agilent 19091A-115 column. By comparing the order of peaks and the peak positions of some pure compounds, such as benzene, toluene, and naphthalene, in GCFID and GC-MS, the peaks in GC-FID can be labelled as the compounds. In a preliminary experiment, it was confirmed that $99.8 \%$ of benzene in water phase can be recovered by the $\mathrm{CH}_{2} \mathrm{Cl}_{2}$ extraction. Carbon content in the aqueous solution was tested using a total organic carbon analyser (TOC-V CSH, Shimadzu, Kyoto, Japan). The molecular mass distribution was analysed using laser desorption/ionisation high-resolution time-of-flight mass spectrometry with a spiral ion trajectory (LDI Spiral-TOFMS, JES-S3000, Jeol, Tokyo, Japan). 
The yield of carbon in Residue 1 was calculated as in equation (2), and the yield of carbon in Residue 2 and Gas 2 was calculated as in equation (3). Here $\mathrm{C}_{\text {Total }}, \mathrm{C}_{\text {Residure } 1}, \mathrm{C}_{\text {Liquid 1 }}, \mathrm{C}_{\mathrm{Gas} \mathrm{1}}$, $\mathrm{C}_{\text {Residue } 2}$ and Gas 2, and $\mathrm{C}_{\text {Liquid } 2}$ mean the total carbon in coal, carbon in Residue 2, carbon in Liquid 1, carbon in Gas 1, carbon in Residue 2 and Gas 2, and carbon in Liquid 2, respectively.

$\mathrm{C}_{\text {Residue 1 }}=\mathrm{C}_{\text {Total }}-\mathrm{C}_{\text {Liquid 1 }}-\mathrm{C}_{\text {Gas 1 }}$

$\mathrm{C}_{\text {Residue } 2 \text { and Gas } 2}=\mathrm{C}_{\text {Liquid 1 }}-\mathrm{C}_{\text {Liquid } 2}$

For decarboxylation of the model aromatic carboxylic acid, two kinds of yield are defined here. The "decarboxylation yield" of the model carboxylic acid is defined as the molar amount of carbon dioxide produced divided by the molar amount of carboxylic functional groups in the acid, as in equation (4).

Decarboxylation yield of acid $=$

Moles of produced $\mathrm{CO}_{2}$ /Moles of $-\mathrm{COOH}$ in acids $\times 100 \%$

The "conversion yield" of the decarboxylation reactions is defined as the molar amount of the reacted reactant (acid) divided by the molar amount of total reactant (acid), as in equation (5). Conversion yield of decarboxylation reaction $=$

Moles of reacted reactant/Moles of total reactant $\times 100 \%$

The method to analyse the carboxylic acids or ions in aqueous solution is shown here. The aqueous solution was acidified by sulphuric acid until the $\mathrm{pH}$ value reached 1.5. After filtration, the remaining transparent solution was extracted with 2-butanone. The extracted 2butanone solution was evaporated at $40^{\circ} \mathrm{C}$ in vacuum completely. After drying at $40^{\circ} \mathrm{C}$ for 24 $\mathrm{h}$ in a vacuum, solid product was formed and redissolved in a small amount of water. Finally, this aqueous solution was analysed by GC-MS and GC-FID directly.

\section{Results and Discussion}

\subsection{Hydrothermal decarboxylation of benzene carboxylic acids}

Based on the chromatogram of $\mathrm{CH}_{2} \mathrm{Cl}_{2}$-recovered products, shown in Figure $1 \mathrm{a}-\mathrm{f}$, GC-MS chromatograms in Figure S1 a-f and corresponding results shown in Table 2, it was found that benzene was the sole product of all benzene carboxylic acids using the $\mathrm{Cu}_{2} \mathrm{O}-\mathrm{SbCW}$ system. Thus, the method described here showed $100 \%$ selectivity in the conversion of benzene carboxylic acids with one to three carboxylic functional groups to benzene and carbon dioxide. Since no undesired products were obtained, the molar yields of benzene were determined from those of carbon dioxide, represented by the decarboxylation yields shown in Table 2.

$O$-phthalic acid, isophthalic acid and terephthalic acid are typical benzene dicarboxylic acids. Without the catalyst, the decarboxylation yield of $o$-phthalic acid was $49.5 \%$, much higher than any other benzene carboxylic acid under the same conditions. The products after the experiments contained only benzoic acid and benzene, based on the GC-MS chromatograms of products dissolved in $\mathrm{CH}_{2} \mathrm{Cl}_{2}$ and water in Figures S2a and S3a.

As shown in Figure 2, the conversion yield of the decarboxylation reaction from $o$-phthalic acid to benzoic acid (reaction (II)) was $96.7 \%$, which is almost complete conversion. This result agrees with a previous report that, when run at $300^{\circ} \mathrm{C}$ for $60 \mathrm{~min}$, the conversion yield of reaction (II) was 72\%.[15] After $\mathrm{Cu}_{2} \mathrm{O}$ was added, the decarboxylation yield of $o$-phthalic acid increased to $92.8 \%$ and benzene was the only product observed, indicating that the majority of benzoic acid formed from the decarboxylation of $O$-phthalic acid was decarboxylated to benzene with the $\mathrm{Cu}_{2} \mathrm{O}$ catalyst. However, the conversion yield of decarboxylation reaction (II) hardly changed, as shown in Figure 2.

Benzoic acid and benzene were the only products of isophthalic acid and terephthalic acid after the hydrothermal decarboxylation without a catalyst at $350^{\circ} \mathrm{C}$ for $60 \mathrm{~min}$, and were 
present in the GC-MS chromatograms of products dissolved in $\mathrm{CH}_{2} \mathrm{Cl}_{2}$ and water in Figures $\mathrm{S} 2 \mathrm{~b}$-c and S3 b-c. The decarboxylation yields of isophthalic acid and terephthalic acid were as low as $2.1 \%$ and $3.6 \%$, shown in runs b-1 and c-1 of Table 2, suggesting that both isophthalic acid and terephthalic acid were stable in subcritical water, consistent with previous reports.[15] However, the decarboxylation yields approached $100 \%$ after $\mathrm{Cu}_{2} \mathrm{O}$ was added, at 98.6 and $97.7 \%$ for isophthalic acid and terephthalic acid, respectively. Except reaction (I), the conversion yields of reaction (III) and (IV) also increased greatly, as shown in Figure 2. It can be demonstrated that the $\mathrm{Cu}_{2} \mathrm{O}-\mathrm{SbCW}$ system is effective not only for the decarboxylation of benzoic acid to benzene but also that from benzene dicarboxylic acids to benzoic acid.

From runs d-1 and e- 1 in Table 2, it can be seen that hemimellitic acid and trimellitic acid had similar stabilities in subcritical water due to their similar decarboxylation yields of $26.9 \%$ and $24.2 \%$, respectively. However, using $\mathrm{Cu}_{2} \mathrm{O}$, both decarboxylation yields increased greatly, to more than $90 \%$, with benzene as the sole product. It is interesting to study the decarboxylation of hemimellitic acid and trimellitic acid to their corresponding dicarboxylic acids.

For hemimellitic acid, after the decarboxylation of one carboxylic functional group, the possible products include $o$ - phthalic acid and isophthalic acid, corresponding to reactions (V) and (VI). Because the decarboxylation yield of $o$-phthalic acid (marked as DY-a), the decarboxylation yield of isophthalic acid (marked as DY-b), and the decarboxylation yield of hemimellitic acid (marked as DY-d) are known, the conversion yield of reaction (V) (marked as $\mathrm{CY}-\mathrm{V}$ ) has a linear relationship with the conversion yield of reaction (VI) (marked as CY$\mathrm{VI})$, as shown in equation (6).

$\mathrm{CY}-\mathrm{V} \times(1+2 \times \mathrm{DY}-\mathrm{a})+\mathrm{CY}-\mathrm{VI} \times(1+2 \times \mathrm{DY}-\mathrm{b})=3 \times \mathrm{DY}-\mathrm{d}$

In Figure 3, the black and red lines represent the relationship between the conversion yields of reaction (V) and (VI) without and with $\mathrm{Cu}_{2} \mathrm{O}$ respectively. It is easy to find the increase in both of the conversion yields of reaction (V) and (VI) using $\mathrm{Cu}_{2} \mathrm{O}$. Additionally, the decarboxylation from hemimellitic acid to dicarboxylic acids is almost complete after the use of $\mathrm{Cu}_{2} \mathrm{O}$.

The decarboxylation of trimellitic acid is complicated, because three dicarboxylic acids are obtained after removing one carboxylic functional group. Depending on the relationship between the decarboxylation yields of $o$-phthalic acid (DY-a), isophthalic acid (DY-b), terephthalic acid (DY-c), and trimellitic acid (DY-e), and the conversion yields of reaction (VII) (CY-VII), reaction (VIII) (CY-VIII), and reaction (IX) (CY-IX), shown in equation (7), the relationships among the conversion yields of reaction (VII), (VIII), and (IX) are as shown in Figure 4.

$$
\begin{gathered}
\mathrm{CY}-\mathrm{VII} \times(1+2 \times \mathrm{DY}-\mathrm{a})+\mathrm{CY}-\mathrm{VIII} \times(1+2 \times \mathrm{DY}-\mathrm{b})+\mathrm{CY}-\mathrm{IX} \times(1+2 \times \mathrm{DY}-\mathrm{c})= \\
3 \times \mathrm{DY}-\mathrm{e}
\end{gathered}
$$

Without using of $\mathrm{Cu}_{2} \mathrm{O}$, up to $70 \%$ of trimellitic acid can be converted to dicarboxylic acids, as supported by previous reports.[15] Catalysed by $\mathrm{Cu}_{2} \mathrm{O}$, almost all the trimellitic acid was decomposed to dicarboxylic acids.

Trimesic acid shows very high stability in subcritical water. Without catalyst, there is almost no product from the decarboxylation reaction based on the GC-MS chromatograms of products dissolved in $\mathrm{CH}_{2} \mathrm{Cl}_{2}$ and water in Figures $\mathrm{S} 2 \mathrm{f}$ and $\mathrm{S} 3 \mathrm{f}$, and the almost-zero decarboxylation yield is displayed in run $\mathrm{f}-1$ in Table 2 . This quite low decarboxylation yield can be explained by the low conversion yields of reaction (X) and (III), shown in Figure 2, at $4.9 \%$ and $4.1 \%$, respectively. The conversion yield of trimesic acid was near $100 \%$ after the addition of $\mathrm{Cu}_{2} \mathrm{O}$, with an increase in the conversion yields of reactions (X) and (III) to about $100 \%$, and there was no other compound in the products other than benzene, shown in Figures S1f and S4f. 


\subsection{Hydrothermal decarboxylation of naphthalene carboxylic acids}

From the chromatogram of $\mathrm{CH}_{2} \mathrm{Cl}_{2}$-recovered products shown in Figure $1 \mathrm{~g}$-i, the GC-MS chromatograms in Figure S1 g-i, and the corresponding results shown in Table 2, it was found that naphthalene was the major product after the decarboxylation of naphthalene carboxylic acids using the $\mathrm{Cu}_{2} \mathrm{O}-\mathrm{SbCW}$ system. Although naphthalene is not the sole product for 2naphthoic acid and 2,6-naphthalic acid, the amount of carbon dioxide produced still equals the decarboxylated carboxylic functional groups. Thus, the decarboxylation yields of naphthalene carboxylic acids can be determined based on the amount of carbon dioxide, as shown in Table 2 .

Based on a past report on 1-naphthoic acid, it was mentioned that in water, the yield of naphthalene decarboxylated from 1-naphthoic acid was $11.6 \%$ at $250^{\circ} \mathrm{C}$ for 5.5 days, and increased to $100 \%$ at $343^{\circ} \mathrm{C}$ for $120 \mathrm{~min}$, without by-product formation.[29] However, in our experiments, there was still a large amount of 1-naphthoic acid after hydrothermal decarboxylation at $350^{\circ} \mathrm{C}$ for 60 or $120 \mathrm{~min}$, with the decarboxylation yields as low as $18.2 \%$ and $32.7 \%$, respectively. However, even after the 60 -min reaction time, the decarboxylation yield of 1-naphthoic acid or the conversion yield of reaction (XI) increased greatly, to $79.1 \%$, after the addition of $\mathrm{Cu}_{2} \mathrm{O}$, and naphthalene became the sole product, supporting the efficiency of $\mathrm{Cu}_{2} \mathrm{O}$.

Without a catalyst, only naphthalene was in the $\mathrm{CH}_{2} \mathrm{Cl}_{2}$-recovered product after hydrothermal treatment of 2-naphthoic acid, as shown in Figures S2h and S3h. The decarboxylation yield was as low as $7.0 \%$, similar to a previous report at $5.7 \%$ at the same temperature.[30] This indicated that the stability of 2-naphthoic acid under hydrothermal conditions was high compared with 1-naphthoic acid. After the addition of $\mathrm{Cu}_{2} \mathrm{O}$, the decarboxylation yield increased greatly, to $69.5 \%$, and there was no peak of 2-naphthoic acid from the GC-MS chromatograms of $\mathrm{CH}_{2} \mathrm{Cl}_{2}$ and $\mathrm{H}_{2} \mathrm{O}$ phase, as shown in Figures $\mathrm{S} 1 \mathrm{~h}$ and $\mathrm{S} 4 \mathrm{~h}$, but some byproducts appeared: e.g., 2,2'-binaphthalene. This is the first identification of a by-product using the $\mathrm{Cu}_{2} \mathrm{O}-\mathrm{SbCW}$ system for the decarboxylation of aromatic carboxylic acids. It is possible that the $\mathrm{Cu}_{2} \mathrm{O}-\mathrm{SbCW}$ system is useful and effective for reaction (XII), but some decompositions or other types of decarboxylation reactions may also occur.

2,6-Naphthalic acid also showed high stability under hydrothermal conditions at $350^{\circ} \mathrm{C}$ for 60 min, with about $2 \%$ decarboxylation yield, corresponding to a previous report.[15] This result can be attributed to the low conversion yields of both reaction (XIII) and (XII), as shown in Figure 2. After $\mathrm{Cu}_{2} \mathrm{O}$ was used, the decarboxylation yield increased to $77.3 \%$ and the peak of 2-naphthoic acid disappeared in the GC-MS chromatograms in Figure S1i, together with the appearance of by-product 2,2'-binaphthalene, which can be attributed to other reactions along with reaction (XII). Because there is no new by-product (excluding 2,2'-binaphthalene found in the products), it can be seen that the $\mathrm{Cu}_{2} \mathrm{O}-\mathrm{SbCW}$ system is effective for the decarboxylation reaction from 2,6-naphthalic acid to 2-naphthoic acid (reaction (XIII)), with a conversion yield of $91.2 \%$, and 2-naphthoic acid as the sole product.

It can be concluded that for all the model aromatic carboxylic acids studied, the decarboxylation yield increased greatly after the use of the $\mathrm{Cu}_{2} \mathrm{O}$ catalyst. Especially for benzene carboxylic acids, all the decarboxylation yields were greater than $90 \%$ with $100 \%$ selectivity. Additionally, based on the conversion yields of all the decarboxylation reactions from (II) to (XIII), shown in Figures 2, 3 and 4, the $\mathrm{Cu}_{2} \mathrm{O}-\mathrm{SbCW}$ system was shown to be effective not only for the decarboxylation from monocarboxylic acid to hydrocarbon, but also for the decarboxylation from polycarboxylic acid to monocarboxylic acid.

\subsection{Hydrothermal oxidation and hydrothermal decarboxylation of LY}


This is the first reported hydrothermal oxidation and catalytic hydrothermal decarboxylation of LY. A traditional $\mathrm{O}_{2}-\mathrm{NaOH}$ hydrothermal oxidation process was used without optimisation of all the parameters to achieve the high yield. As an initial study, we focused on the effectiveness of $\mathrm{Cu}_{2} \mathrm{O}$ or $\mathrm{Cu}_{2} \mathrm{O}-\mathrm{SbCW}$ system.

Figure 5 shows the carbon balance through the hydrothermal oxidation and hydrothermal decarboxylation of LY. In the hydrothermal oxidation process, the carbon percentages of Gas 1 and Residue 1 were 20.7 and $29.0 \%$, respectively, and $33.5 \%$ of carbon was left in Residue 2 and Gas 2. This result indicated that more than $80 \%$ of carbon in coal was not utilized as the feed of the hydrothermal decarboxylation process, suggesting that the parameters in the oxidation process needed to be optimised. In the decarboxylation process, it was found that after using of $\mathrm{Cu}_{2} \mathrm{O}$, the yield of Gas 3 increased almost four-fold. As the decarboxylation process was performed under the same conditions, the only possible explanation was that with $\mathrm{Cu}_{2} \mathrm{O}$, the decarboxylation reactions were promoted, emitting a large volume of $\mathrm{CO}_{2}$.

To study the reactions during the decarboxylation process, it is significant to analyse the compounds in the products. Figure 6 shows the GC-MS results of $\mathrm{CH}_{2} \mathrm{Cl}_{2}$-recovered products after the hydrothermal oxidation and hydrothermal decarboxylation of LY without and with a $\mathrm{Cu}_{2} \mathrm{O}$ catalyst. Various aromatic hydrocarbons and heterocyclic compounds were observable in both of two samples, but also there are some significant differences. The first big difference was the yield of benzene. Without $\mathrm{Cu}_{2} \mathrm{O}$, there was almost no benzene. Calculated from the results of GC-FID, as shown in Figure S5, the yield of benzene was as low as $0.03 \mathrm{~g} / \mathrm{kg}$-coal. After using the $\mathrm{Cu}_{2} \mathrm{O}$ catalyst, the yield of benzene increased to $3.80 \mathrm{~g} / \mathrm{kg}$-coal, more than 100 -fold. Beyond benzene, the yield of many valuable products increased clearly with the addition of the $\mathrm{Cu}_{2} \mathrm{O}$ catalyst, such as pyridine, toluene, benzaldehyde, phenol, acetophenone, naphthalene, dibenzo[b,d]furan, $9 H$-fluorene, and $9 H$-fluoren-9-one. For example, the yield of pyridine increased from 0.56 to $1.56 \mathrm{~g} / \mathrm{kg}$-coal. The second difference was the appearance of many new hydrocarbons after the use of $\mathrm{Cu}_{2} \mathrm{O}$. These included ethylbenzene, xylene, prop1-en-2-ylbenzene, methylnaphthalene, allylbenzene, cumene, 1,1'-biphenyl, 3-methyl-1,1'biphenyl, diphenylmethane, 3-methyl-1,1'-biphenyl, anthracene, and phenanthrene, as shown in Figure 6. This indicated that the hydrothermal oxidation and catalytic hydrothermal decarboxylation method was a promising method for the production of benzene and other aromatic hydrocarbons from brown coal.

There is a need for evidence that the benzene and other aromatic hydrocarbons were formed from the decarboxylation of aromatic carboxylic acids. Because the aromatic carboxylic acids and ions were dissolved in water, it is important to analyse the $\mathrm{H}_{2} \mathrm{O}$-phase products. However, from GC-MS results of $\mathrm{H}_{2} \mathrm{O}$-phase products after hydrothermal oxidation and hydrothermal decarboxylation of LY, as shown in Figure S6, only phenol and phenolic compounds were found, which does not provide any evidence for the existence of decarboxylation reactions. To demonstrate the existence of the decarboxylation reaction and to study the reaction mechanism during the decarboxylation process, aromatic carboxylic acids or ions in Liquid 2 and $\mathrm{H}_{2} \mathrm{O}$-phase products should be tested directly. The carboxylic acids or ions in aqueous solutions including Liquid 2 and two $\mathrm{H}_{2} \mathrm{O}$-phase products after the hydrothermal decarboxylation process without and with $\mathrm{Cu}_{2} \mathrm{O}$, were analysed and shown in Figure 7.

From the chromatogram and the determined compounds in Figure 7, many different carboxylic acids and oxygen heterocyclic compounds were found in the reactants and products during the decarboxylation process. When attention was focused on the aromatic carboxylic acids, it was interesting to see changes. In the reactants, shown in Figure 7a, there are many aromatic carboxylic acids with more than three carboxylic functional groups, such as pyromellitic acid. After hydrothermal treatment without $\mathrm{Cu}_{2} \mathrm{O}$, there is almost no pyromellitic 
acid, and more carboxylic acids with one or two carboxylic acids appeared, such as 4acetylbenzoic acid, methyl benzoic acid, 3-hydroxybenzoic acid, and terephthalic acid, as shown in Figure 7b. Based on the GC-MS results of the $\mathrm{CH}_{2} \mathrm{Cl}_{2}$-recovered products after the hydrothermal oxidation and hydrothermal decarboxylation process (shown in Figure 6a), there was almost no benzene, indicating that the decarboxylation reaction was mainly from polycarboxylic acids to polycarboxylic acids with less carboxylic functional groups or monocarboxylic acids.

As compared to Figure 7b, Figure 7c showed the disappearance of polycarboxylic acids and that aromatic monocarboxylic acids represented by benzoic acid became the main product after using $\mathrm{Cu}_{2} \mathrm{O}$. Meanwhile, a large amount of benzoic acid was decarboxylated to benzene, which can be proven by the GC-FID chromatogram in Figure S5b and GC-MS chromatogram in Figure 6b. From these results, it was demonstrated that decarboxylation reactions were the main reactions during the decarboxylation process, and that the use of $\mathrm{Cu}_{2} \mathrm{O}$ was not only effective for decarboxylation of monocarboxylic acids but also of polycarboxylic acids to monocarboxylic acids. This result corresponds with the decarboxylation of the model aromatic carboxylic acids. In addition, it was speculated that during the decarboxylation process using $\mathrm{Cu}_{2} \mathrm{O}$, the conversion from polycarboxylic acids to monocarboxylic acids has a higher reaction rate than that from monocarboxylic acids to hydrocarbons, which led to the uncomplete conversion of benzoic acid to benzene.

It is known that coal products are usually a complex mixture, including light compounds with low molecular weights and heavy compounds with high molecular weights. From our past research, it has been shown that LDI-MS is an important tool in the characterisation of heavy compounds.[31] Figures 8a and b show the LDI-MS spectra of $\mathrm{CH}_{2} \mathrm{Cl}_{2}$-recovered products without and with the $\mathrm{Cu}_{2} \mathrm{O}$ catalyst, respectively. In the low mass range of Figure 8a, two main peaks at $\mathrm{m} / \mathrm{z} 94$ and $\mathrm{m} / \mathrm{z} 108$ dominate the mass spectrum. The elemental compositions of these species were $\mathrm{C}_{6} \mathrm{H}_{6} \mathrm{O}\left(\mathrm{m} / \mathrm{z}\right.$ 94) and $\mathrm{C}_{7} \mathrm{H}_{8} \mathrm{O}(\mathrm{m} / \mathrm{z}$ 108). In the "high" mass range ( $>150 \mathrm{Da})$ of Figure $8 \mathrm{a}$, a complex pattern was detected, exhibiting a Gaussian-like shape with an average mass computed around $300 \mathrm{Da}$. By contrast, only the low mass range peaks are observed in Figure $8 \mathrm{~b}$, while the "high" mass range appears full depleted. This result indicated that the $\mathrm{Cu}_{2} \mathrm{O}$ catalyst was also effective for the conversion of heavy to light compounds. To determine whether those reactions of heavy compounds to light compounds are decarboxylation reactions, further evidence is needed.

From the current results, at the early stages of the hydrothermal oxidation and hydrothermal decarboxylation processes, it is sufficient to predict that this method is promising for the production of benzene and other aromatic hydrocarbons from brown coal in a water medium, after further optimisation of the parameters.

\section{Conclusions}

Here, we proposed a novel hydrothermal process for the production of aromatic hydrocarbons from brown coal - with no use of hydrogen or hydrogen donor - that consists of hydrothermal oxidation and catalytic hydrothermal decarboxylation at $\leq 350^{\circ} \mathrm{C}$. The validity of the decarboxylation method was examined using several aromatic carboxylic acids as model compounds for the acid products after the hydrothermal oxidation of brown coal, including $O$ phthalic acid, isophthalic acid, terephthalic acid, hemimellitic acid, trimellitic acid, trimesic acid, 1-naphthoic acid, 2-naphthic acid, and 2,6-naphthalic acid. The decarboxylation yields of all the model aromatic carboxylic acids were enhanced greatly by the use of a $\mathrm{Cu}_{2} \mathrm{O}$ catalyst. Especially for benzene polycarboxylic acids, all decarboxylation yields were greater than 
$90 \%$, with $100 \%$ selectivity. The $\mathrm{Cu}_{2} \mathrm{O}-\mathrm{SbCW}$ system was shown to be effective not only for the decarboxylation reactions from monocarboxylic acids to hydrocarbons, but also for the decarboxylation reactions from tricarboxylic acids to dicarboxylic acids and those from dicarboxylic acids to monocarboxylic acids. Using the 'traditional' alkali-oxygen hydrothermal oxidation process, a variety of aromatic hydrocarbons and heterocyclic compounds, especially benzene, were obtained from LY by hydrothermal oxidation and a catalytic hydrothermal decarboxylation process. Analyses of aromatic carboxylic acids or ions before and after the decarboxylation process indicated that the decarboxylation reactions were the major reactions and the use of $\mathrm{Cu}_{2} \mathrm{O}$ was effective not only for decarboxylation from monocarboxylic acids, but also from polycarboxylic acids to monocarboxylic acids, which corresponded with the results with the model aromatic carboxylic acids. Additionally, the $\mathrm{Cu}_{2} \mathrm{O}$ catalyst was found to be effective for the conversion of 'heavy' compounds in oxidised coal to 'light' compounds, which needs to be studied further. Together, these results show that the hydrothermal oxidation and catalytic hydrothermal decarboxylation method is promising for the production of valuable aromatic hydrocarbons from brown coal in a water medium without the use of hydrogen or hydrogen donors, subject to improvement of the catalyst and further optimisation of parameters.

\section{Acknowledgements}

This work was supported by JST and the Strategic International Collaborative Research Program (SICORP). The authors thank Dr. Thierry Fouquet and Dr. Hiroaki Sato of Environmental Management Research Institute in National Institute of Advanced Industrial Science and Technology (AIST) for their LDI-MS analyses.

\section{References}

[1] K. Miura, Mild conversion of coal for producing valuable chemicals, Fuel Process Technol, 62 (2000) 119-135.

[2] C.-Z. Li, Chapter 1 - Introduction, in: C.-Z. Li (Ed.) Advances in the Science of Victorian Brown Coal, Elsevier Science, Amsterdam, 2004, pp. 1-10.

[3] J. Entel, NUCLEAR STRUCTURE OF THE WATER-SOLUBLE POLYCARBOXYLIC ACIDS FROM THE OXIDATION OF BITUMINOUS COAL - THE DECARBOXYLATION REACTION, J Am Chem Soc, 77 (1955) 611-615.

[4] L.M. Stock, M. Obeng, Oxidation and decarboxylation. A reaction sequence for the study of aromatic structural elements in Pocahontas No. 3 coal, Energ Fuel, 11 (1997) 987-997.

[5] R.S. Montgomery, E.D. Holly, Structures of the Acids Obtained by Oxidation of Bituminous Coal - Thermal Decarboxylation of the Copper Salts, Fuel, 36 (1957) 493-500.

[6] K. Mae, H. Shindo, K. Miura, A new two-step oxidative degradation method for producing valuable chemicals from low rank coals under mild conditions, Energ Fuel, 15 (2001) 611-617.

[7] R. Dabestani, P.F. Britt, A.C. Buchanan, Pyrolysis of aromatic carboxylic acid salts: Does decarboxylation play a role in cross-linking reactions?, Energ Fuel, 19 (2005) 365-373.

[8] Y. Kamiya, Partial Decarboxylation of Aromatic Polycarboxylic Acids from the Oxidation of Coal, Fuel, 42 (1963) 347-352.

[9] D.W. Krevelen, Coal--typology, Physics, Chemistry, Constitution, Elsevier, 1993.

[10] C.H. Ruof, T.R. Savich, H.C. Howard, NUCLEAR STRUCTURE OF THE WATERSOLUBLE POLYCARBOXYLIC ACIDS FROM OXIDATION OF BITUMINOUS COAL, J Am Chem Soc, 73 (1951) 3873-3879. 
[11] N.W. Franke, M.W. Kiebler, C.H. Ruof, T.R. Savich, H.C. Howard, Water-Soluble Polycarboxylic Acids by Oxidation of Coal, Ind Eng Chem, 44 (1952) 2784-2792.

[12] Y. Kamiya, Formation of Aromatic Polycarboxylic Acids from Bituminous Coal by OxygenOxidation in Alkaline Medium, Fuel, 40 (1961) 149-153.

[13] K. Mae, T. Maki, J. Araki, K. Miura, Extraction of low-rank coals oxidized with hydrogen peroxide in conventionally used solvents at room temperature, Energ Fuel, 11 (1997) 825-831.

[14] R. Pietrzak, H. Wachowska, The influence of oxidation with HNO3 on the surface composition of high-sulphur coals: XPS study, Fuel Process Technol, 87 (2006) 1021-1029.

[15] J.B. Dunn, M.L. Burns, S.E. Hunter, P.E. Savage, Hydrothermal stability of aromatic carboxylic acids, J Supercrit Fluid, 27 (2003) 263-274.

[16] J. Cornella, C. Sanchez, D. Banawa, I. Larrosa, Silver-catalysed protodecarboxylation of orthosubstituted benzoic acids, Chem Commun, (2009) 7176-7178.

[17] L.J. Goossen, C. Linder, N. Rodriguez, P.P. Lange, A. Fromm, Silver-catalysed protodecarboxylation of carboxylic acids, Chem Commun, (2009) 7173-7175.

[18] L.J. Goossen, N. Rodriguez, C. Linder, P.P. Lange, A. Fromm, Comparative Study of Copperand Silver-Catalyzed Protodecarboxylations of Carboxylic Acids, Chemcatchem, 2 (2010) 430-442. [19] G. Cahiez, A. Moyeux, O. Gager, M. Poizat, Copper-Catalyzed Decarboxylation of Aromatic Carboxylic Acids: En Route to Milder Reaction Conditions, Adv Synth Catal, 355 (2013) 790-796. [20] X.Y. Toy, I.I. Bin Roslan, G.K. Chuah, S. Jaenicke, Protodecarboxylation of carboxylic acids over heterogeneous silver catalysts, Catal Sci Technol, 4 (2014) 516-523.

[21] J.S. Dickstein, C.A. Mulrooney, E.M. O'Brien, B.J. Morgan, M.C. Kozlowski, Development of a catalytic aromatic decarboxylation reaction, Org Lett, 9 (2007) 2441-2444.

[22] L.J. Goossen, N. Rodriguez, C. Linder, Decarboxylative Biaryl Synthesis from Aromatic Carboxylates and Aryl Triflates, J Am Chem Soc, 130 (2008) 15248-15249.

[23] S. Bhadra, W.I. Dzik, L.J. Goossen, Decarboxylative Etherification of Aromatic Carboxylic Acids, J Am Chem Soc, 134 (2012) 9938-9941.

[24] A. Fromm, C. van Wullen, D. Hackenberger, L.J. Goossen, Mechanism of Cu/Pd-Catalyzed Decarboxylative Cross-Couplings: A DFT Investigation, J Am Chem Soc, 136 (2014) 1000710023.

[25] P.F. Lu, C. Sanchez, J. Cornella, I. Larrosa, Silver-Catalyzed Protodecarboxylation of Heteroaromatic Carboxylic Acids, Org Lett, 11 (2009) 5710-5713.

[26] S. Matsubara, Y. Yokota, K. Oshima, Palladium-catalyzed decarboxylation and decarbonylation under hydrothermal conditions: Decarboxylative deuteration, Org Lett, 6 (2004) 2071-2073.

[27] Q. Zheng, M. Morimoto, T. Takanohashi, An efficient production of benzene from benzoic acid in subcritical water using a copper(i) oxide catalyst, Green Chem, 17 (2015) 791-794.

[28] W.H. Wang, Y.C. Hou, W.Z. Wu, M.G. Niu, T. Wu, High-Temperature Alkali-Oxygen Oxidation of Lignite to Produce Benzene Polycarboxylic Acids, Ind Eng Chem Res, 52 (2013) 680685.

[29] M. Siskin, G. Brons, S.N. Vaughn, A.R. Katritzky, M. Balasubramanian, Aqueous OrganicChemistry .3. Aquathermolysis - Reactivity of Ethers and Esters, Energ Fuel, 4 (1990) 488-492.

[30] L. Artok, H.H. Schobert, Reaction of carboxylic acids under coal liquefaction conditions - 1. Under nitrogen atmosphere, J Anal Appl Pyrol, 54 (2000) 215-233.

[31] Q.X. Zheng, M. Morimoto, H. Sato, T. Takanohashi, Molecular composition of extracts obtained by hydrothermal extraction of brown coal, Fuel, 159 (2015) 751-758. 
Table 1. Ultimate and proximate analyses of LY coal.

\begin{tabular}{cccccccccc}
\hline & \multicolumn{4}{c}{ ultimate analysis } & \multicolumn{3}{c}{ proximate analysis } \\
{$[\mathrm{wt} \%, \mathrm{daf}]$} & & \multicolumn{3}{c}{$\begin{array}{c}\text { moisture } \\
\text { coal name }\end{array}$} \\
\cline { 2 - 10 } & $\mathrm{C}$ & $\mathrm{H}$ & $\mathrm{N}$ & $\mathrm{S}$ & $\mathrm{O} *$ & $\mathrm{FC}$ & $\mathrm{VM}$ & $\mathrm{Ash}$ & \\
\hline $\mathrm{LY}$ & 66.6 & 5.3 & 0.5 & 0.2 & 27.4 & 50.4 & 48.1 & 1.5 & 58.4 \\
\hline
\end{tabular}

*: by difference. 
Table 2. Experimental results of hydrothermal decarboxylation of model aromatic carboxylic acids at $350^{\circ} \mathrm{C}$ for $60 \mathrm{~min}$.

\begin{tabular}{|c|c|c|c|c|c|c|c|}
\hline $\operatorname{Run}^{[\mathrm{a}]}$ & $\begin{array}{c}\mathrm{Cu} / \mathrm{COOH} \\
{[\mathrm{mol} \%]}\end{array}$ & $\begin{array}{c}\text { acid/water } \\
{[\mathrm{wt} \%]}\end{array}$ & $\begin{array}{c}\text { density }^{[\mathrm{b}]} \\
{[\mathrm{g} / \mathrm{mL}]}\end{array}$ & $\begin{array}{c}\text { pressure } \\
{[\mathrm{MPa}]}\end{array}$ & $\begin{array}{c}\text { decarboxylation } \\
\text { yield } \\
{[\%]}\end{array}$ & $\begin{array}{c}\text { compounds in } \mathrm{CH}_{2} \mathrm{Cl}_{2} \\
\text { phase } \\
\end{array}$ & $\begin{array}{c}\text { compounds in } \mathrm{H}_{2} \mathrm{O} \\
\text { phase } \\
\text { [c] [d] }\end{array}$ \\
\hline$a-1$ & 0 & 5 & 0.6 & $20.7-22.9$ & $49.5 \pm 2.1$ & $\begin{array}{c}\text { benzene, } \\
\text { benzoic acid }\end{array}$ & benzoic acid \\
\hline$a-2$ & 100 & 5 & 0.6 & $21.0-23.0$ & $92.8 \pm 1.2$ & benzene & benzene* \\
\hline$b-1$ & 0 & 5 & 0.6 & $17.7-20.0$ & $2.1 \pm 0.5$ & $\begin{array}{c}\text { benzene, } \\
\text { benzoic acid }\end{array}$ & benzoic acid \\
\hline$b-2$ & 100 & 5 & 0.6 & $22.5-24.7$ & $98.6 \pm 0.2$ & benzene & none \\
\hline $\mathrm{c}-1$ & 0 & 5 & 0.6 & 18.9-20.7 & $3.6 \pm 1.9$ & $\begin{array}{c}\text { benzene, } \\
\text { benzoic acid }\end{array}$ & benzoic acid \\
\hline $\mathrm{c}-2$ & 100 & 5 & 0.6 & $22.5-24.0$ & $97.7 \pm 4.1$ & benzene & none \\
\hline d-1 & 0 & 5 & 0.6 & $21.2-22.5$ & $26.9 \pm 2.5$ & $\begin{array}{c}\text { benzene, } \\
\text { benzoic acid }\end{array}$ & benzoic acid \\
\hline$d-2$ & 100 & 5 & 0.6 & $21.0-22.4$ & $94.8 \pm 6.5$ & benzene & none \\
\hline e-1 & 0 & 5 & 0.6 & $21.2-23.0$ & $24.2 \pm 0.2$ & benzoic acid & benzoic acid \\
\hline$e-2$ & 100 & 5 & 0.6 & $22.5-23.7$ & $93.0 \pm 8.8$ & benzene & none \\
\hline$f-1$ & 0 & 5 & 0.6 & 17.8-19.4 & $1.7 \pm 0.1$ & none & none \\
\hline$f-2$ & 100 & 5 & 0.6 & $21.5-23.3$ & $99.1 \pm 1.0$ & benzene & benzene* \\
\hline $\mathrm{g}-1$ & 0 & 5 & 0.6 & $20.1-23.5$ & $18.2 \pm 0.2$ & $\begin{array}{l}\text { naphthalene, } \\
\text { 1-naphthoic acid }\end{array}$ & $\begin{array}{l}\text { naphthalene, } \\
\text { 1-naphthoic acid }\end{array}$ \\
\hline $\mathrm{g}-2$ & 100 & 5 & 0.6 & $22.2-23.0$ & $79.1 \pm 5.9$ & naphthalene & none \\
\hline h-1 & 0 & 5 & 0.6 & $21.5-21.8$ & $7.0 \pm 0.1$ & $\begin{array}{l}\text { naphthalene, } \\
\text { 2-naphthoic acid }\end{array}$ & $\begin{array}{c}\text { naphthalene, } \\
\text { 2-naphthoic acid }\end{array}$ \\
\hline $\mathrm{h}-2$ & 100 & 5 & 0.6 & $22.2-23.0$ & $69.5 \pm 2.3$ & $\begin{array}{c}\text { naphthalene, } \\
\text { 2,2'-binaphthalene* }\end{array}$ & none \\
\hline $\mathrm{i}-1$ & 0 & 5 & 0.6 & $19.6-21.4$ & $1.8 \pm 0.1$ & $\begin{array}{l}\text { naphthalene, } \\
\text { 2-naphthoic acid }\end{array}$ & $\begin{array}{l}\text { naphthalene*, } \\
\text { 2-naphthoic acid }\end{array}$ \\
\hline $\mathrm{i}-2$ & 100 & 5 & 0.6 & $21.7-22.3$ & $77.3 \pm 1.5$ & $\begin{array}{c}\text { naphthalene, } \\
\text { 2,2'-binaphthalene* }\end{array}$ & none \\
\hline
\end{tabular}

[a] Here a, b, c, d, e, f, g, h, and i correspond to o-phthalic acid, isophthalic acid, terephthalic acid, hemimellitic acid, trimellitic acid, trimesic acid, 1-naphthoic acid, 2-naphthoic acid, and 2,6-naphthalic acid, respectively. [b] Density was calculated as the total mass of feed (acid, water, and catalyst) divided by the volume of autoclave. [c] $\mathrm{CH}_{2} \mathrm{Cl}_{2}$ exists in all water phases. [d] Compounds were determined using GC-MS. *: trace amounts. 


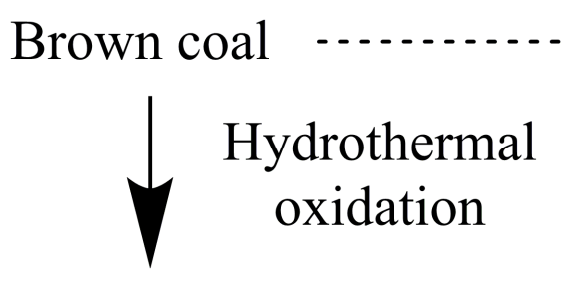

Aromatic carboxylic acids

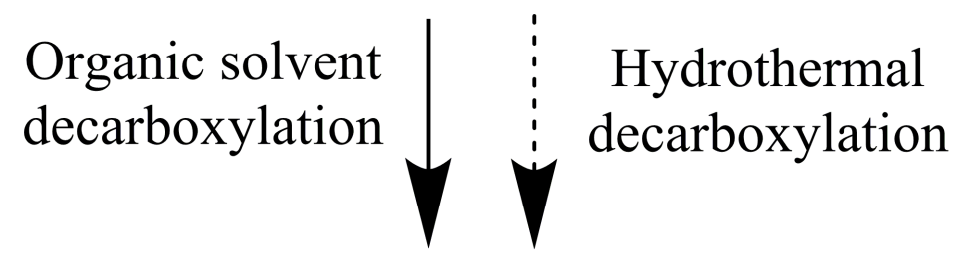

Two-step Hydrothermal conversion

\section{Aromatic hydrocarbons}

Scheme 1. Concept of hydrothermal oxidation and hydrothermal decarboxylation process for the production of aromatic hydrocarbons from brown coal. 


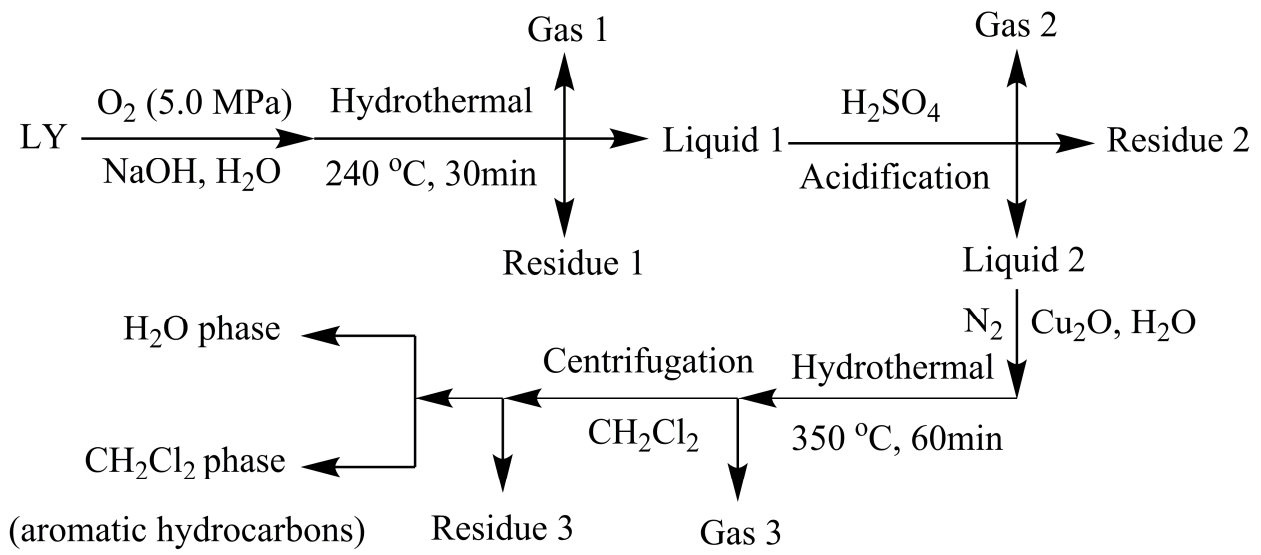

Scheme 2. Hydrothermal oxidation and hydrothermal decarboxylation process for the production of aromatic hydrocarbons from LY. 

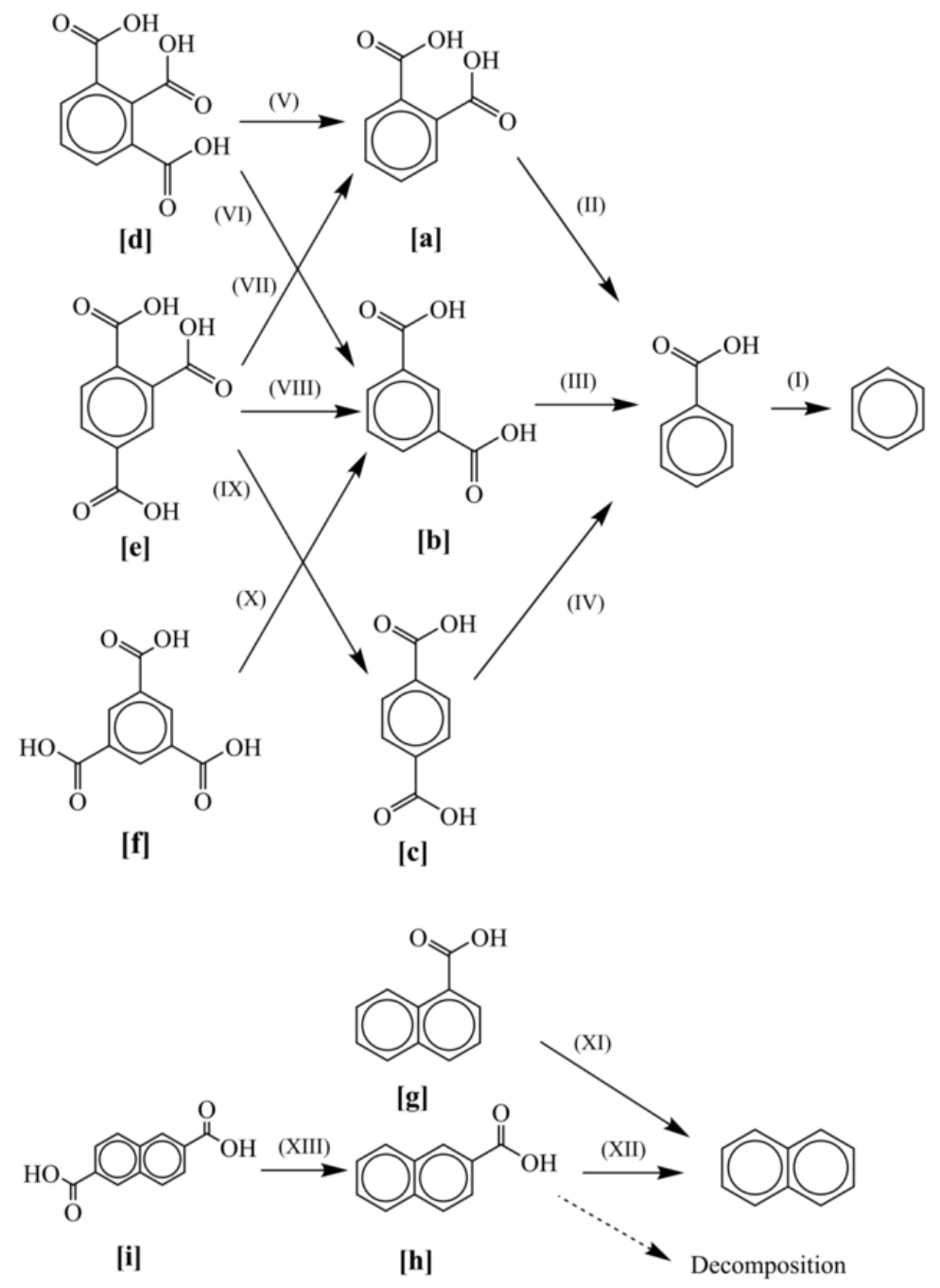

Chart 1. Information about the model aromatic carboxylic acids and conversion yield of different decarboxylation reactions without and with $\mathrm{Cu}_{2} \mathrm{O}$. (1) Structures of model aromatic carboxylic acids: [a] $o$-phthalic acid, [b] isophthalic acid, [c] terephthalic acid, [d] hemimellitic acid, [e] trimellitic acid, [f] trimesic acid, [g] 1-naphthoic acid, [h] 2-naphthoic acid, [i] 2,6-naphthalic acid, and diagram of all decarboxylation reactions for different acids: (I) from benzoic acid to benzene, (II) from [a] to benzoic acid, (III) from [b] to benzoic acid, (IV) from [c] to benzoic acid, (V) from [d] to [a], (VI) from [d] to [b], (VII) from [e] to [a], (VIII) from [e] to [b], (IX) from [e] to [c], (X) from [f] to [b], (XI) from $[\mathrm{g}]$ to naphthalene, $(\mathrm{XII})$ from $[\mathrm{h}]$ to naphthalene, and (XIII) from [i] to [h]. 


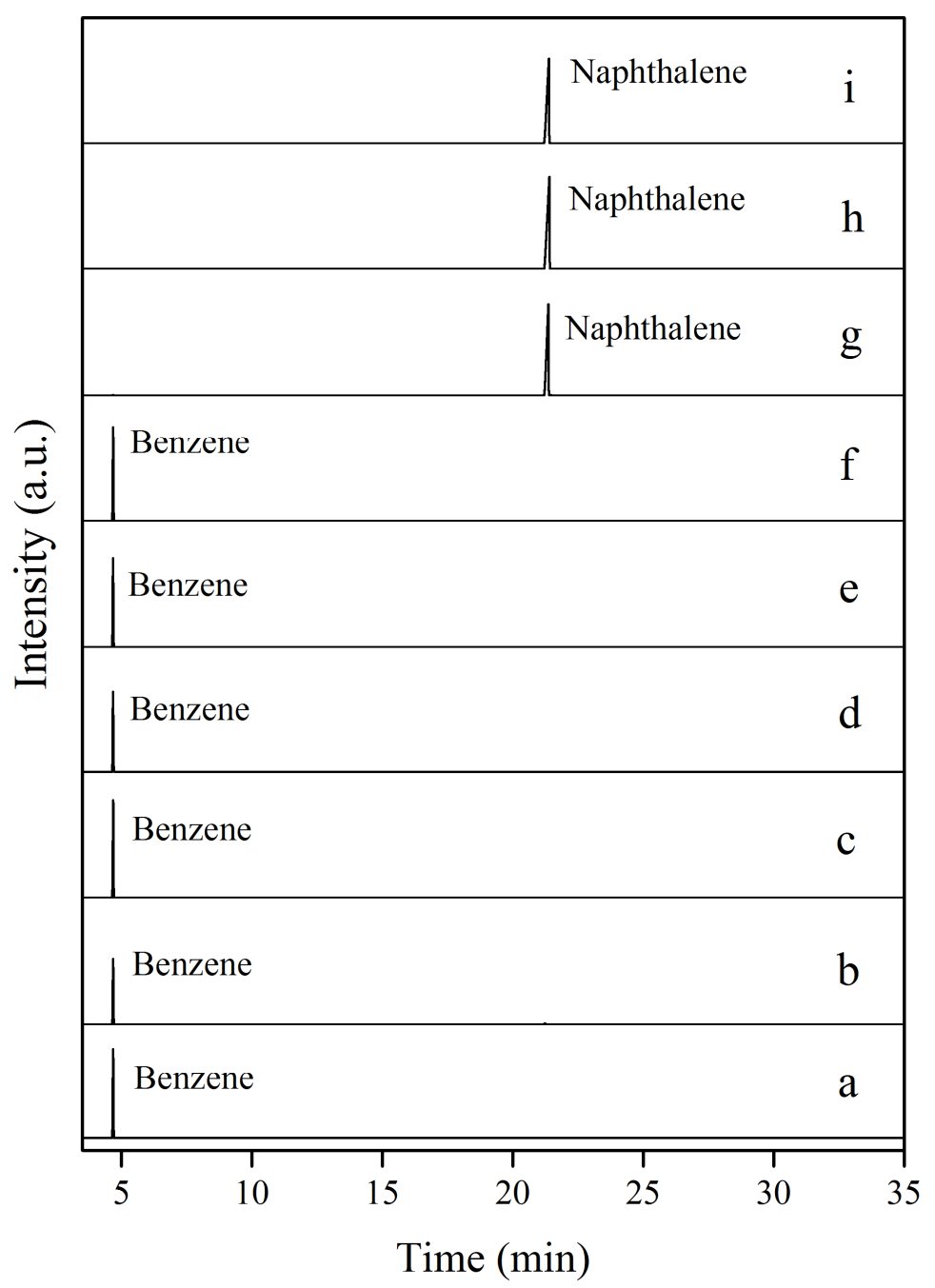

Figure 1. Gas chromatograph-flame ionisation detector (GC-FID) chromatograms of products resolved in $\mathrm{CH}_{2} \mathrm{Cl}_{2}$ after hydrothermal decarboxylation of the following aromatic acids: (a) $o$-phthalic acid, (b) isophthalic acid, (c) terephthalic acid, (d) hemimellitic acid, (e) trimellitic acid, (f) trimesic acid, (g) 1-naphthoic acid, (h) 2-naphthoic acid, and (i) 2,6-naphthalic acid. 


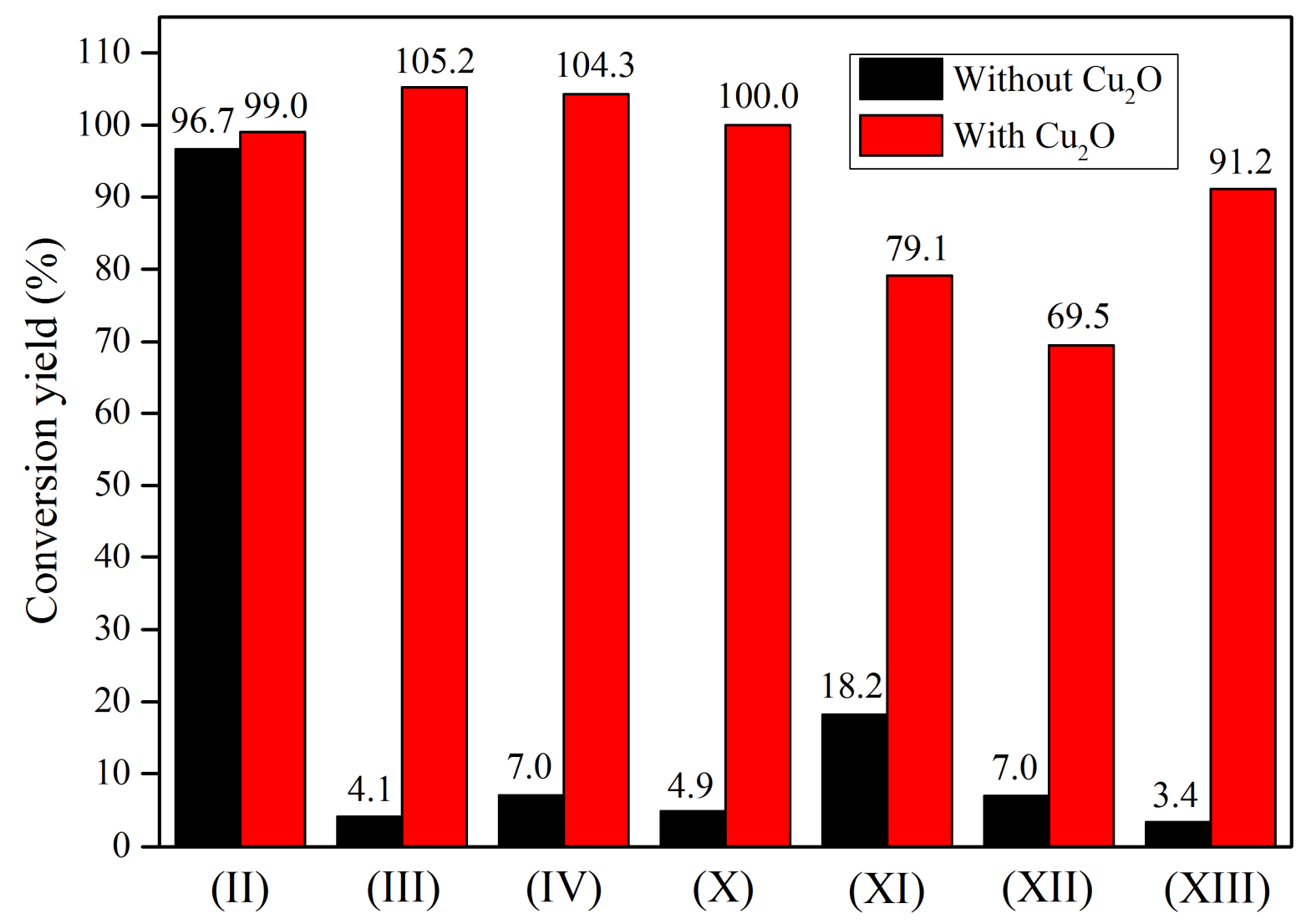

Figure 2. The conversion yields of the decarboxylation reactions II, III, IV, X, XI, XII, and XIII without and with $\mathrm{Cu}_{2} \mathrm{O}$. Reactions II, III, IV, X, XI, XII, and XIII mean the decarboxylation reactions from $o$-phthalic acid to benzoic acid, from isophthalic acid to benzoic acid, from terephthalic acid to benzoic acid, from trimesic acid to isophthalic acid, from 1-naphthoic acid to naphthalene, from 2naphthoic acid to naphthalene, and from 2,6-naphthalic acid to 2-naphthoic acid, respectively. 


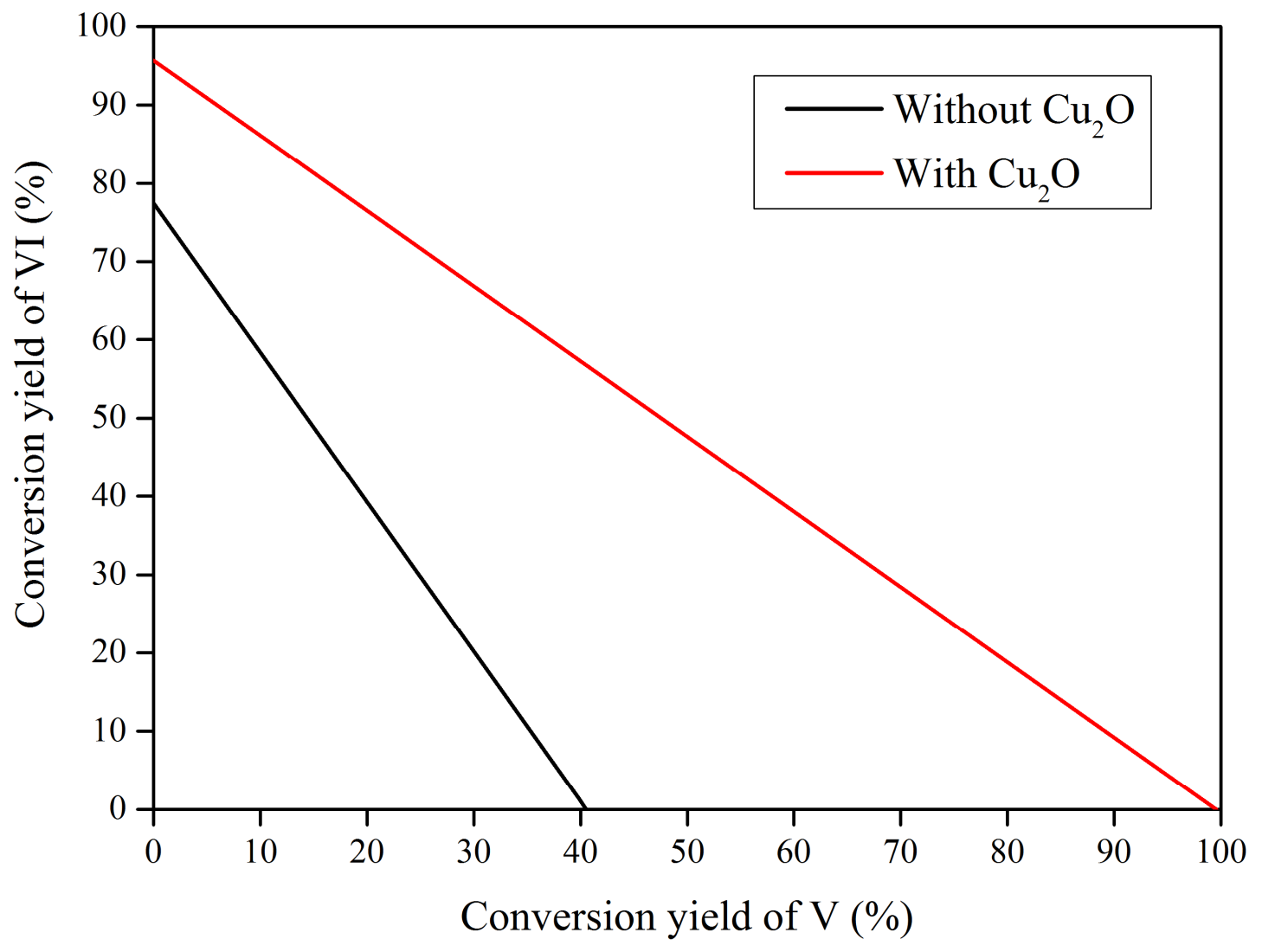

Figure 3. The relationship between the conversion yields of reaction V and VI. Reactions V and VI mean the decarboxylation reactions from hemimellitic acid to $o$-phthalic acid and from hemimellitic acid to isophthalic acid. 


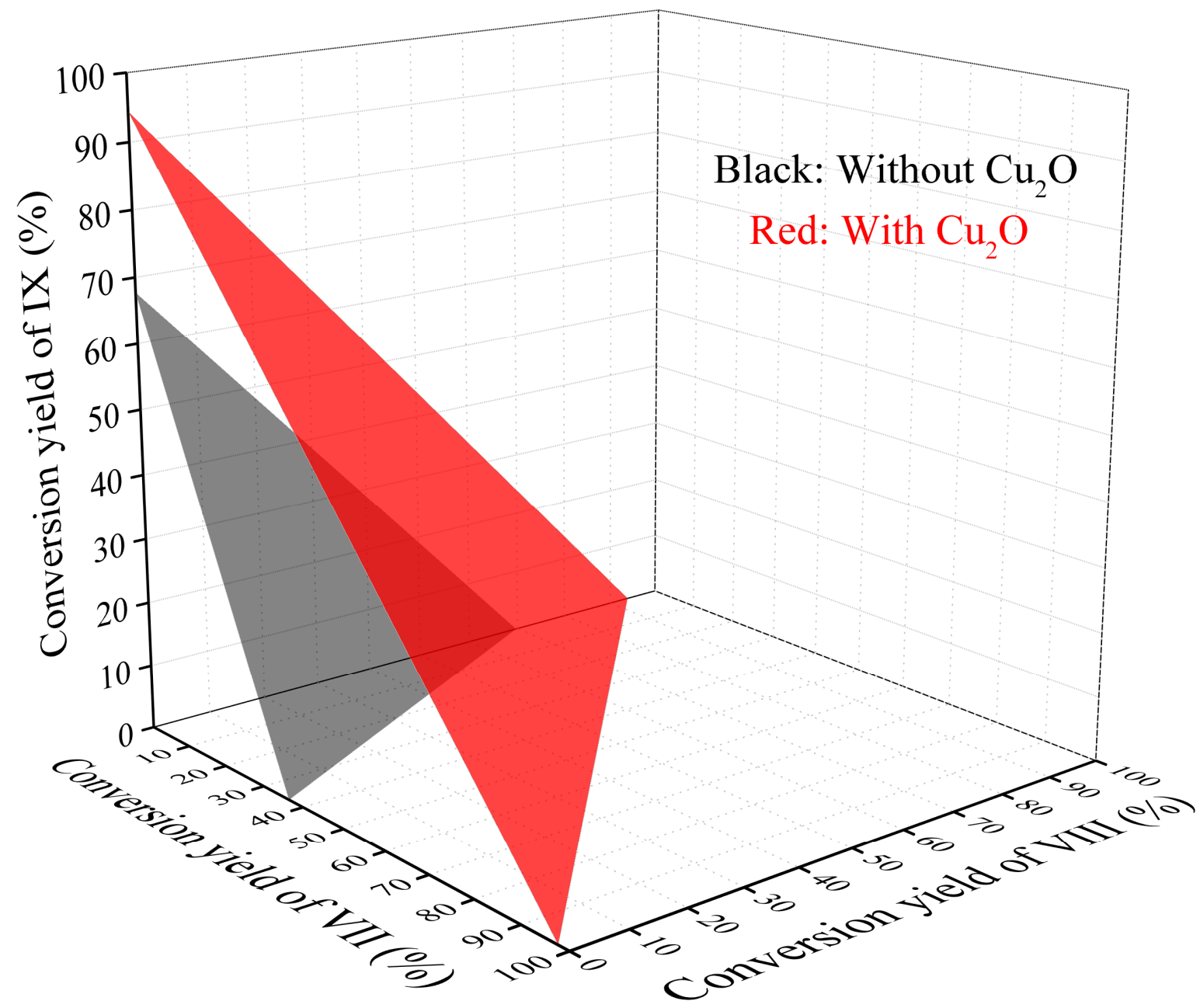

Figure 4. The relationship between the conversion yields of reaction VII, VIII, and IX. Reactions VII, VIII, and IX mean the decarboxylation reactions from $o$-phthalic acid, from trimellitic acid to isophthalic acid, and from trimellitic acid to terephthalic acid. 


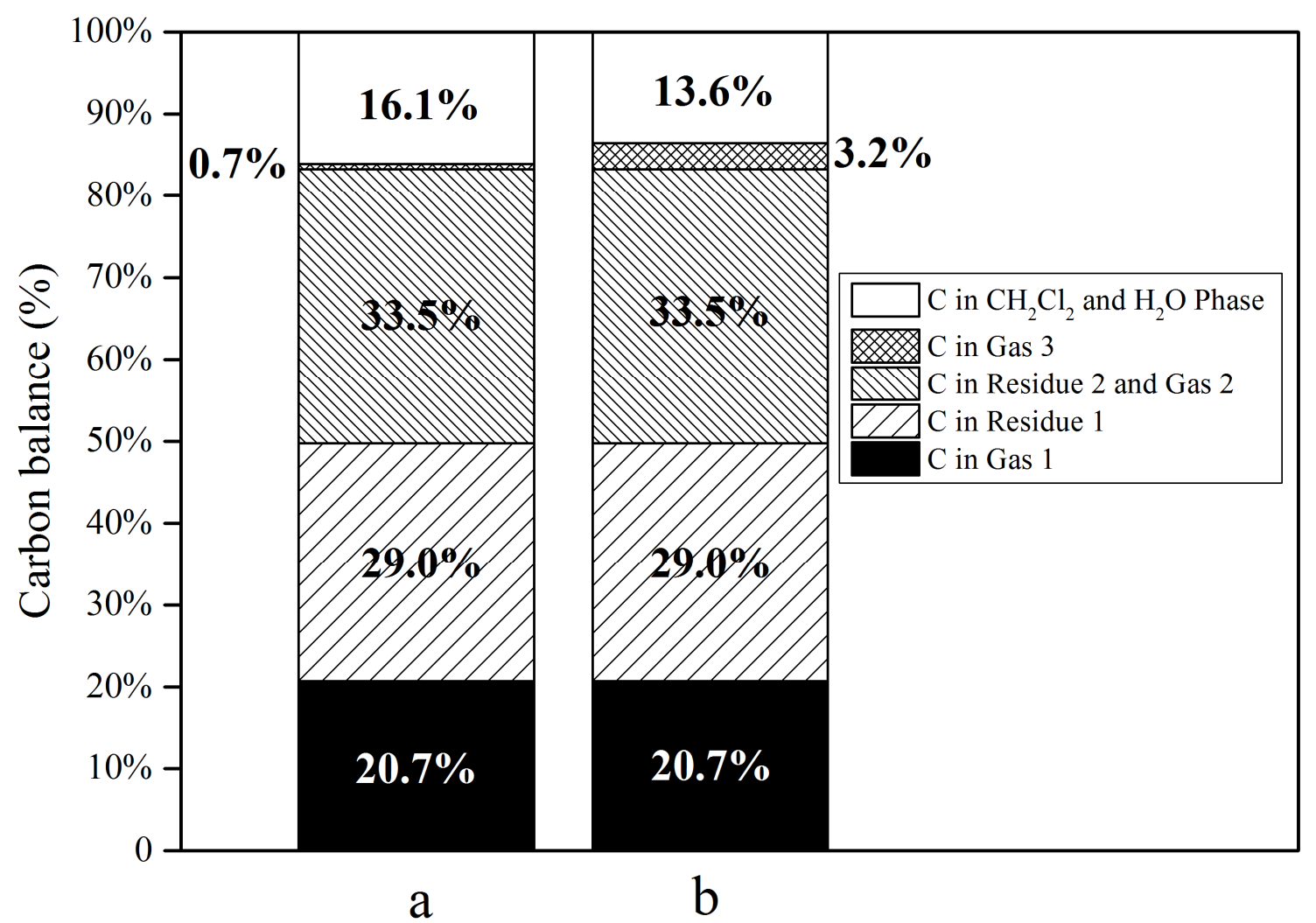

Figure 5. Carbon balance through the hydrothermal oxidation and hydrothermal decarboxylation of LY (a) without $\mathrm{Cu}_{2} \mathrm{O}$ and (b) with $\mathrm{Cu}_{2} \mathrm{O}$. Carbon in $\mathrm{CH}_{2} \mathrm{CH}_{2}$ and $\mathrm{H}_{2} \mathrm{O}$ phase was calculated by the difference. 


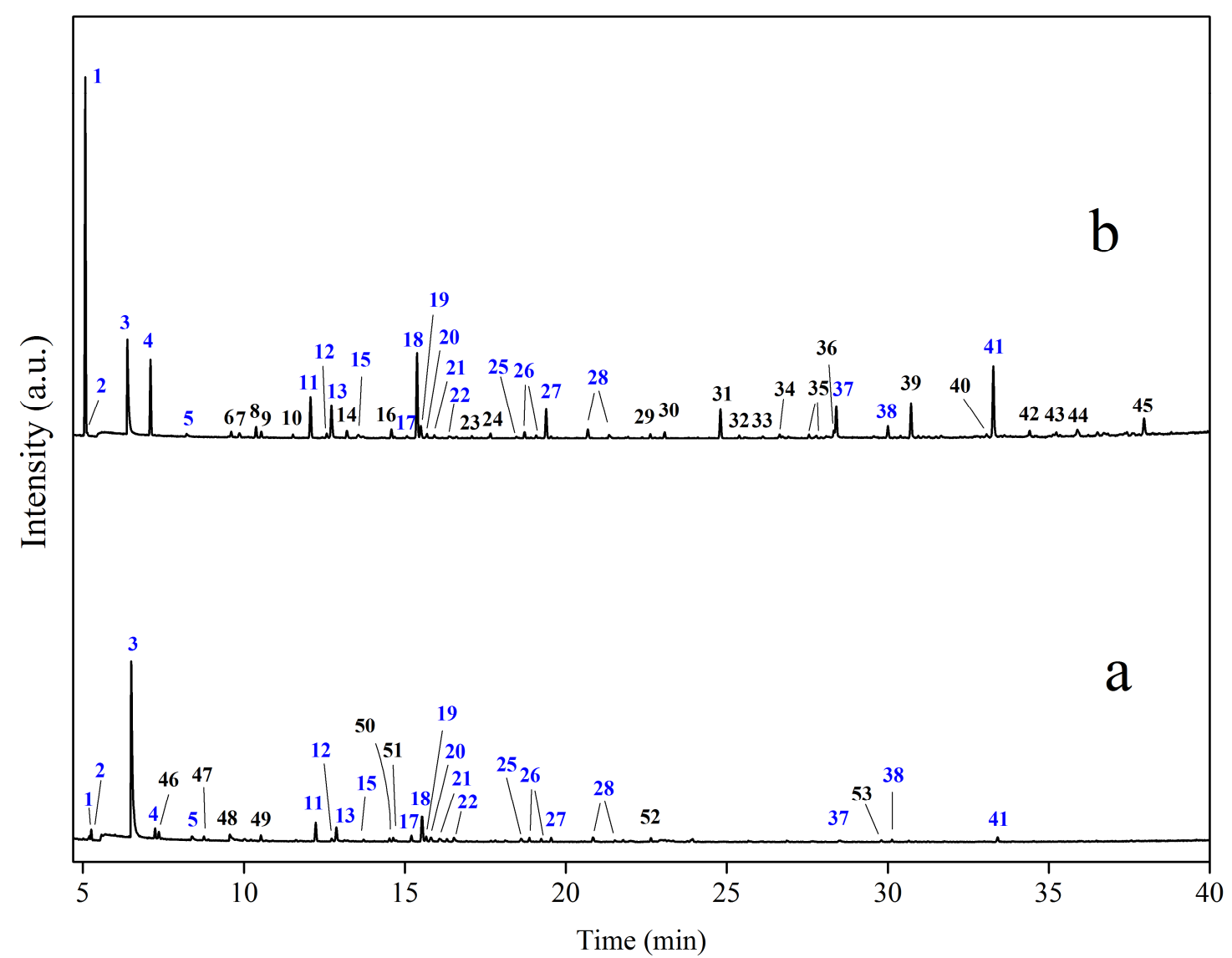

Figure 6. Gas chromatography-mass spectrometry (GC-MS) chromatogram of $\mathrm{CH}_{2} \mathrm{Cl}_{2}$-recovered products after hydrothermal oxidation and hydrothermal decarboxylation of Loy Yang coal (LY) (a) without $\mathrm{Cu}_{2} \mathrm{O}$ and (b) with $\mathrm{Cu}_{2} \mathrm{O}$. Determined compounds included: 1 benzene, 2 thiophene, 3 pyridine, 4 toluene, 53 -methylpyridine, 6 ethylbenzene, $7 o$-xylene, 8 styrene, $9 m$-xylene, 10 cumene, 11 benzaldehyde, 12 4-methylpyridine, 13 phenol, 14 prop-1-en-2-ylbenzene, 15 benzofuran, 16 allylbenzene, $17 o$-cresol, 18 acetophenone, 19 4-methylbenzaldehyde, $20 \mathrm{p}$-cresol, 21 2-methylbenzaldehyde, 22 1-(pyridin-3-yl)ethan-1-one, 23 2-methylbenzofuran, 24 1-(otolyl)ethan-1-one, 25 isobenzofuran-1(3H)-one, 26 acetyltoluene, 27 naphthalene, 28 quinoline, 29 2-methylnaphthalene, 30 1-methylnaphthalene, 31 1,1'-biphenyl, 32 3-methyl-1,1'-biphenyl, 33 diphenylmethane, 34 phenylpyridine, 35 3-methyl-1,1'-biphenyl, 36 2,6-di-tert-butyl-4methylphenol, 37 dibenzo[b,d]furan, $389 H$-fluorene, 39 benzophenone, 40 phenyl(mtolyl)methanone, $419 H$-fluoren-9-one, 42 anthracene or phenanthrene, 43 anthracen-9(10H)-one, 44 9H-xanthen-9-one, 45 anthracene-9,10-dione, 46 cyclopentanone, 47 2-methylcyclopentan-1-one, 48 2-methylpyridine, 49 2-methylcyclopent-2-en-1-one, 50 phenylmethanol, 51 2,3-dimethylcyclopent2-en-1-one, 52 3-methyl-2,3-dihydro- $1 H$-inden-1-one, and 53 diethyl phthalate. *Blue colour means the same compounds existed in both samples. 


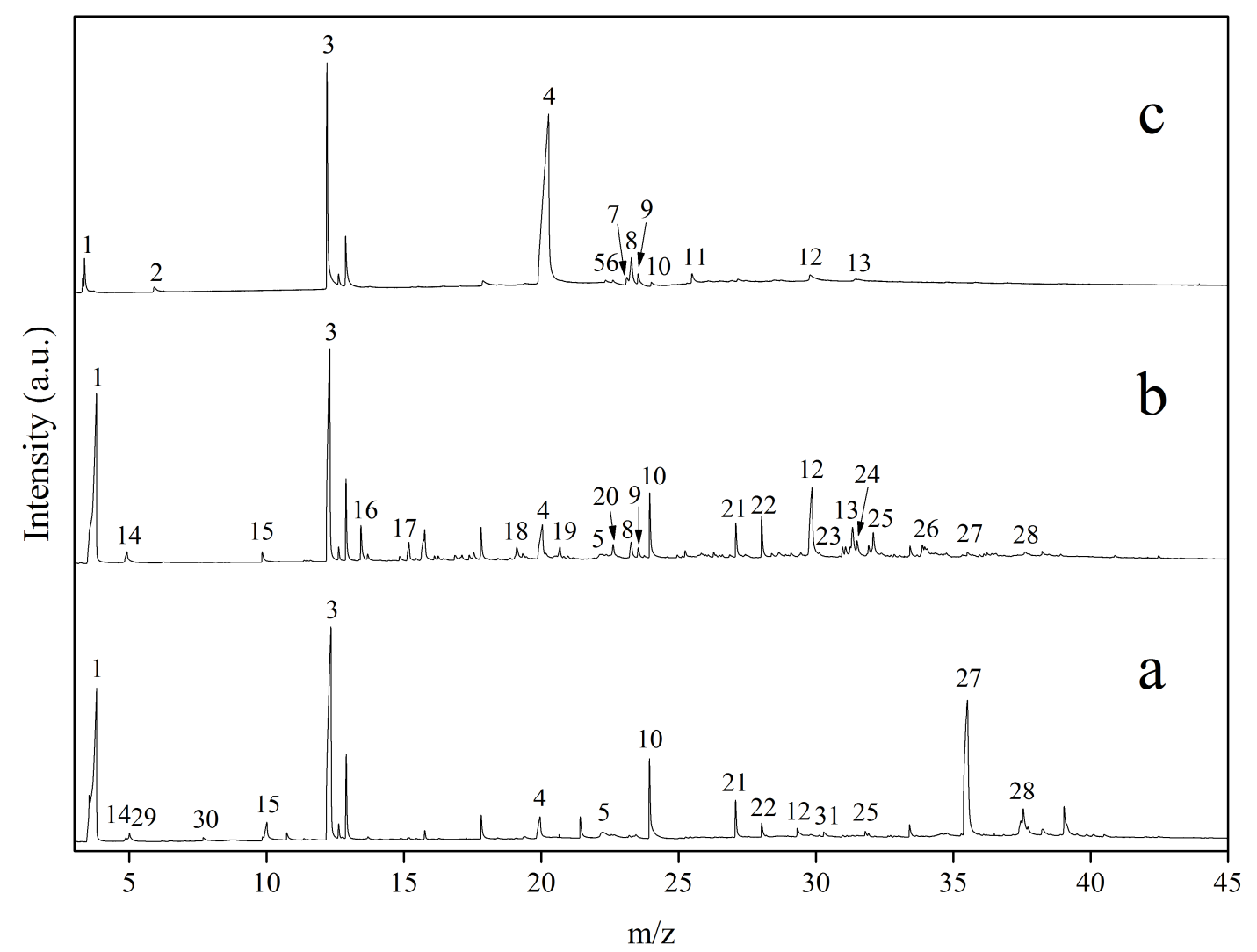

Figure 7. GC-FID chromatogram of acids in (a) oxidised coal and $\mathrm{H}_{2} \mathrm{O}$-phase product after hydrothermal oxidation and hydrothermal decarboxylation of $\mathrm{LY}$ (b) without $\mathrm{Cu}_{2} \mathrm{O}$ and (c) with $\mathrm{Cu}_{2} \mathrm{O}$. Compounds determined by GC-MS included: 1 acetic acid, 2 pyridine, 3 succinic anhydride, 4 benzoic acid, 5 picolinic acid, 6 glutaric acid, 7 diethyl succinate, 8 3-methylbenzoic acid, 94 methylbenzoic acid, $10 o$-phthalic acid, 113 -phenylpropanoic acid, 12 3-hydroxybenzoic acid, 13 4acetylbenzoic acid, 14 propionic acid, 15 butyrolactone, 16 phenol, 17 2,3-dimethylcyclopent-2-en1-one, 18 5-oxohexanoic acid, 19 cyclohex-1-ene-1-carboxylic acid, 20 2-methylbenzoic acid, 21 3Methylphthalic anhydride, 22 4-methylphthalic anhydride, 23 3-methylsalicylic acid, 24 4methylsalicylic acid, 25 4,5-dimethyl-2-benzofuran-1,3-dione, 26 terephthalic acid, 27 pyromellitic acid, 28 trimellitic anhydride, 29 acrylic acid, 30 maleic anhydride, and 31 4,7-dimethyl-2benzofuran-1,3-dione. 


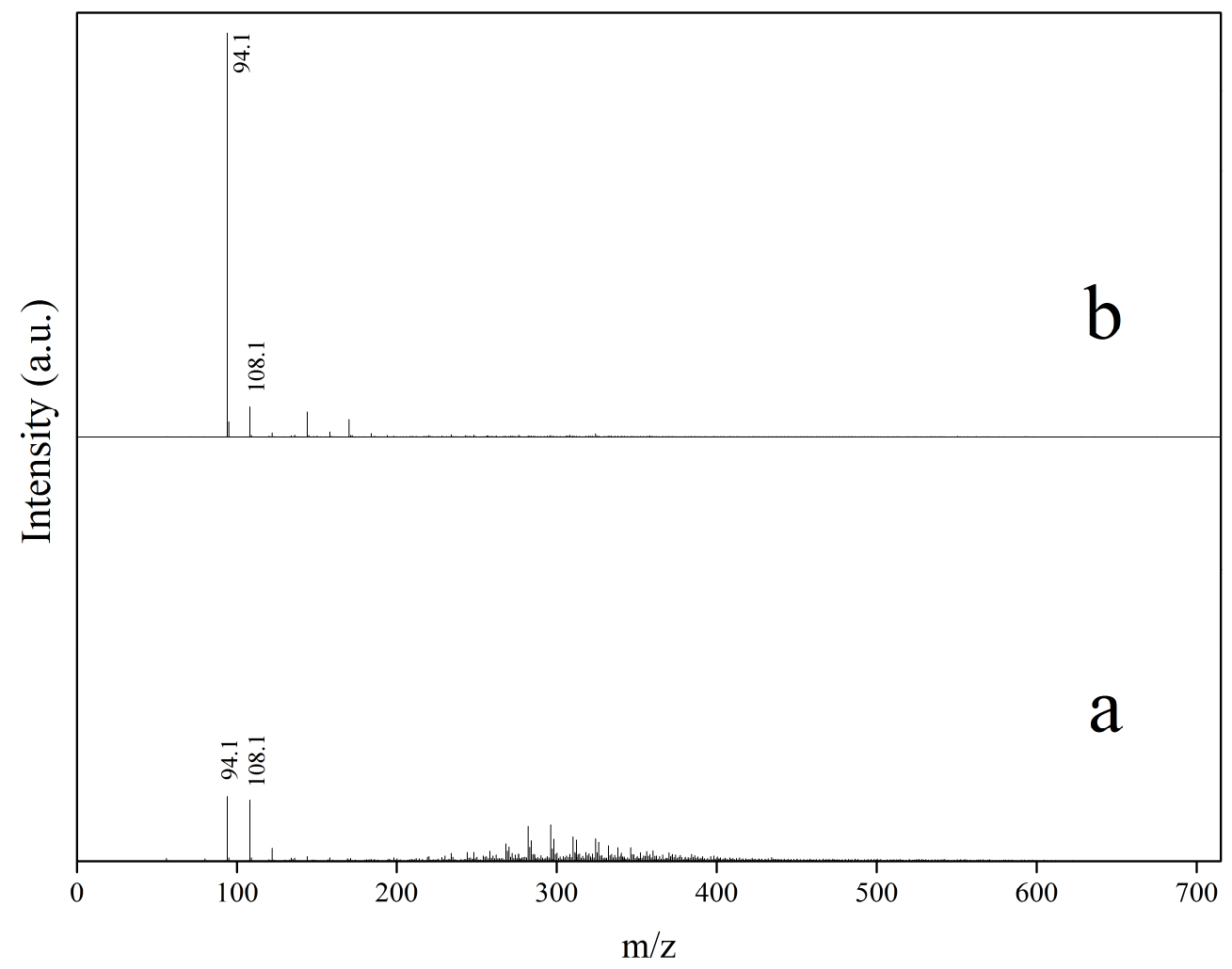

Figure 8. LDI-mass spectra of $\mathrm{CH}_{2} \mathrm{Cl}_{2}$-recovered products after hydrothermal oxidation and hydrothermal decarboxylation of $\mathrm{LY}$ (a) without $\mathrm{Cu}_{2} \mathrm{O}$ and (b) with $\mathrm{Cu}_{2} \mathrm{O}$. The height of $\mathrm{m} / \mathrm{z} 94.1$ was normalised by the concentration of phenol. 